\title{
Impact of Age, Obesity and Smoking on Patient Satisfaction with Breast Implant Surgery - A Unicentric Analysis of 318 Implant Reconstructions after Mastectomy
}

\author{
Der Einfluss von Alter, BMI und Nikotin auf die Patientenzufriedenheit in der Implantatchirurgie - \\ eine unizentrische Untersuchung von 318 Implantatrekonstruktionen nach Mastektomie
}

Authors

Affiliations
P. Kern ${ }^{1,2}$, F. Zarth ${ }^{1}$, R. Kimmig ${ }^{1}$, M. Rezai ${ }^{2}$

${ }^{1}$ Department of Gynecology and Obstetrics; University Hospital Essen, Essen

${ }^{2}$ Breast Center Düsseldorf, Luisenkrankenhaus, Düsseldorf

\section{Key words}

- breast cancer

- implant reconstruction

- influencing factors

aesthetic result

Schlüsselwörter

- Mammakarzinom

- Implantatrekonstruktion

- Einflussfaktoren

- ästhetisches Ergebnis

\section{received 25.4.2015 \\ revised $\quad 5.5 .2015$ \\ accepted $\quad 7.5 .2015$}

Bibliography

DOI http://dx.doi.org/

10.1055/s-0035-1546171

Geburtsh Frauenheilk 2015; 75 :

597-604 @ Georg Thieme

Verlag KG Stuttgart · New York . ISSN 0016-5751

\section{Correspondence}

\section{Peter Kern, M.D.}

Department of Gynecology

and Obstetrics

University Hospital Essen

Hufelandstraße 55

45147 Essen

peter.kern@uk-essen.de

Breast Center Düsseldorf

Dr. Rezai

Hans-Günther-Sohl-Straße 7-10

40235 Düsseldorf

\section{Abstract \\ $\nabla$}

Aim: Breast reconstruction has become increasingly important for the body image of women with breast cancer. We conducted a study to investigate how patient characteristics correlate with surgical outcome after breast reconstruction with implant after mastectomy and to identify risk factors which could facilitate patient selection for reconstruction.

Patients and Methods: For this case cohort analysis ( $n=257$ patients with 318 heterologous reconstructions), we analyzed BMI, smoking, preexisting disease, chemotherapy and radiotherapy, one-stage/two-stage reconstruction, immediate/ delayed reconstruction, antibiotic therapy and complications, partner interaction and adherence to the decision for reconstruction using a customized questionnaire.

Results: 257 patients with 318 implant reconstructions (196 unilateral, 61 bilateral) were eligible for inclusion in the study. Median follow-up time was 3.1 years (range: 1 month to 10 years). Response rate to the questionnaire was $71.8 \%$. Median age was 49 years (range 24-79 years), median BMI was 22.44 (range 16.33-40.09). A BMI > 30 was inversely correlated with positive self-image $(p=0.004)$, and implant loss/rotation was more frequent in this group $(\mathrm{p}<0.05)$. Smoking $>10$ cigarettes/day had a negative impact on surgical outcome. A positive self-image had a positive impact on partner interaction $(\mathrm{p}<0.001)$ and was correlated with a lower perception of pain. Aesthetic results did not vary with age $(\mathrm{p}=0.054)$. Titanized polypropylene meshes were used to protect against implant rotation $(p=0.034)$. Rates of capsular fibrosis were low in our cohort $(<10 \%)$, and implant loss rate was less than $2 \%$.

Conclusions: This study offers a differentiated approach for the pre-surgical counselling of patients and shows that patients up to 80 years of age are

\section{Zusammenfassung \\ $\nabla$}

Ziel: Brustrekonstruktion bekommt eine immer größere Bedeutung für Frauen, die an Brustkrebs erkranken. Wir führten eine Studie zur Korrelation der Patientencharakteristika mit dem Operationsergebnis nach Mastektomie und Implantatrekonstruktion durch, um Risikofaktoren zu identifizieren und eine bessere Patientenselektion für den Rekonstruktionsmodus zu finden.

Patienten und Methoden: Für diese Kohortenanalyse ( $n=257$ Patienten mit 318 heterologen Rekonstruktionen) mit einem studienspezifischen Fragebogen analysierten wir Faktoren wie BMI, Rauchen, vorbestehende Erkrankungen, Durchführung von Chemotherapie und Radiotherapie, ein- bzw. zweizeitige Rekonstruktion, Sofortrekonstruktion oder verzögerte Rekonstruktion, Anwendung von Antibiotika und Komplikationen, Partner-Interaktion und die Adhärenz zur Entscheidung zur Implantatrekonstruktion.

Ergebnisse: 257 Patientinnen mit 318 Implantatrekonstruktionen (196 unilateral, 61 bilateral) wurden eingeschlossen in diese Studie. Das mediane Follow-up war 3,1 Jahre (Range: 1 Monat bis zu 10 Jahren). Die Rücklaufquote der Patientenbefragung durch studienspezifische Fragebögen betrug 71,8\%. Das mediane Alter der Patientinnen war 49 Jahre (Range: 24-79 Jahre), der mediane BMI war 22,44 (Range: 16,33-40,09). Ein $\mathrm{BMI}>30$ und eine positive Selbstwahrnehmung waren invers korreliert ( $p=0,004)$ und Implantatverlust/-rotation waren häufiger in dieser Patientengruppe zu finden. Rauchen von über 10 Zigaretten/Tag hatte einen negativen Einfluss auf das Operationsergebnis. Eine positive Selbstwahrnehmung hatte einen positiven Einfluss auf die Partner-Interaktion $(p<0,001)$ und war mit geringerer Schmerzwahrnehmung korreliert. Das ästhetische Ergebnis war unabhängig vom Alter $(p=0,054)$. Der Gebrauch von titanisierten Polypropylennetzen verhinderte die Implantat- 
highly satisfied with implant reconstruction. A high BMI and smoking > 10 cigarettes/day are unfavorable preconditions for implant reconstruction. The use of prophylactic antibiotics was confirmed as beneficial for surgical outcome. A positive self-image after reconstruction strongly influences partner interaction.

\section{Introduction}

$\nabla$

One of eight women will be diagnosed with breast cancer in the course of her life [1,2]. Around 74500 cases are registered annually in Germany, and breast cancer still is one of the ten most common causes of mortality. While therapy options for breast cancer have evolved [3], surgery remains mandatory for all breast cancer patients. Despite the oncological safety of breast-conserving therapy and radiation for most patients [4,5], mastectomy is necessary for a selected group of patients with large or multicentric tumors or skin involvement, for whom breast conserving therapy is not possible. With mastectomy rates of between 20 and $50 \%$ in some countries, breast reconstruction is an important issue for preserving the body image of affected women. Mastectomy is also associated with a number of quality-of-life issues and physical sequelae [6-8]. In many women who have undergone mastectomy, the wish for aesthetic improvement does not decrease even after long-term follow-up [7].

The decision whether to opt for heterologous or autologous reconstruction needs to be considered with regard to both patient safety and patient satisfaction. The impact of patient characteristics and comorbidities on patient satisfaction still has to be determined. With half of all breast cancer patients younger than 65 years at diagnosis and every 6th woman younger than 50 years [1], increasing numbers of women will desire breast reconstruction.

Fernández-Delgado evaluated the role of breast reconstruction in a cohort of patients who underwent either immediate or delayed reconstruction after mastectomy and found significantly lower levels of stress and anxiety in those women who pursued reconstruction compared to those who did not opt for reconstruction [9].

To facilitate a better patient selection and achieve a higher degree of patient satisfaction with reconstructive results, we analyzed surgical outcome as a function of patient characteristics and comorbidities in a large cohort of post-mastectomy patients who had had implant reconstruction. Patient self-image and the impact of self-image on partner interaction were also analyzed. rotation ( $p=0,034)$. Die Rate von Kapselfibrosen war insgesamt niedrig in unserer Kohorte $(<10 \%)$ und die Implantat-Verlustrate belief sich auf weniger als $2 \%$.

Schlussfolgerung: Die Studienergebnisse ermöglichen eine differenzierte präoperative Aufklärung und Beratung von Patientinnen mit Rekonstruktionswunsch. Sie zeigen, dass bis zu 80 Jahren eine hohe Patientenzufriedenheit mit Implantaten zu erzielen ist. Ein hoher BMI und Rauchen über 10 Zigaretten/Tag sind ungünstige Voraussetzungen für die Durchführung einer Implantatrekonstruktion. Der Nutzen der Antibiotikaprophylaxe in der Implantatchirurgie wurde bestätigt. Die positive Selbstwahrnehmung nach Rekonstruktion beeinflusst stark die Partner-Interaktion.

\section{Patients and Methods \\ $\nabla$}

\section{Patients}

The survey was carried out in a cohort of patients treated consecutively at the Breast Center Düsseldorf, Luisenkrankenhaus. All patients who underwent either immediate or deferred implant reconstruction after mastectomy between 2000 and 2010 were eligible for inclusion in the study. Patients were identified from a prospectively maintained database which registers all patients who have reconstructive breast surgery. The database had datasets for 567 patients who underwent reconstructive surgery in the period stated above. Of those patients, 310 patients were excluded because they had autologous reconstruction $(n=310)$, resulting in study population of 257 implant reconstructions, 97 of which were simultaneous reconstructions and 151 of which were two-stage reconstructions after tissue expander procedures $(n=151)$. The study was approved by the Institutional Review Board (IRB) and complies with the Declaration of Helsinki.

\section{Data collection}

Patient characteristics at the time of diagnosis and data on the initial surgery were obtained from the patients' medical charts. Prospectively documented surgery complications were retrieved from the patients' charts for this analysis.

Patients were asked to complete a customized questionnaire which was sent to patients by regular mail. The questionnaire comprised a set of 60 questions addressing short- and long-term sequelae after surgery, patient satisfaction with the aesthetic outcome, and partner interaction.

Primary endpoint was the correlation between patient characteristics and surgical outcome. Secondary endpoint was the influence of patient characteristics on patient satisfaction. Data were retrieved from patients' medical charts and questionnaires to evaluate aesthetic outcomes and mid- and long-term surgical outcomes.

Table 1 Patient characteristics.

\begin{tabular}{|c|c|c|c|c|c|}
\hline & Minimum & Maximum & Median & Mean & Standard deviation \\
\hline Age & 24 years & 79 years & 49 years & 50.16 years & \pm 10.95 years \\
\hline Height & $148 \mathrm{~cm}$ & $185 \mathrm{~cm}$ & $168 \mathrm{~cm}$ & $167.7 \mathrm{~cm}$ & $\pm 6.46 \mathrm{~cm}$ \\
\hline Weight & $41 \mathrm{~kg}$ & $120 \mathrm{~kg}$ & $65 \mathrm{~kg}$ & $65.71 \mathrm{~kg}$ & $\pm 10.92 \mathrm{~kg}$ \\
\hline BMI & 16.33 & 40.09 & 22.44 & 23.29 & \pm 3.56 \\
\hline
\end{tabular}




\section{Statistics}

For explorative statistical analysis, we used standard univariate methods appropriate to the scale of the variables (e.g. Fisher's Exact test for $\mathrm{n} \times \mathrm{m}$ tables or Mann-Whitney-Wilcoxon test to compare two distributions) and applied a significance level $\alpha$ of $5 \%$ to each test.

\section{Results \\ $\nabla$}

\section{Description of patient cohort}

One hundred and eighty-five out of 257 patients (71.98\%) completed the questionnaire. Mean age was 49 years (range: $24-79$ years). Mean body weight was $65.71 \pm 10.92 \mathrm{~kg}$, and height ranged from 148 to $185 \mathrm{~cm}$ (median: $168 \mathrm{~cm}$; mean: $167.7 \mathrm{~cm}$ $\pm 6.46 \mathrm{~cm}$ ), resulting in a median BMI of 22.44 (range: $16.33-$ 40.09; mean: $23.29 \pm 3.56$ ). Patient characteristics are summarized in $\bigcirc$ Table 1.

One hundred and thirty patients (50.58\%) received chemotherapy, 30 (23\%) of them in a neoadjuvant, and 78 (60\%) in an adjuvant setting; 22 (17\%) patients did not specify the chemotherapy setting. Thirty-five patients (13.62\%) had radiotherapy, 2 of them after implantation of an expander system. Forty-eight of 257 patients were smokers (18.68\%); 9 (3.50\%) of them smoked less than 5 cigarettes per day, 22 (8.56\%) smoked 5-10 cigarettes per day, and 17 (6.62\%) smoked more than 10 cigarettes per day. Seven $(2.72 \%)$ women had been smokers in the past; $2(0.78 \%)$ of them had stopped smoking within the last 3 years, and 5 (1.95\%) had stopped smoking more than 3 years ago. Data analysis was done between 2.37 and 128.6 months (71 to 3858 days) after reconstruction. Follow-up was defined from the date of the last implant reconstruction to the date of sending the questionnaire or the patient's last visit to the clinic. Median follow-up was 36.8 months (mean: $41.29 \pm 26.52$ months). Median time from mastectomy to reconstruction was 6 months (mean: $6.29 \pm 2.9$ months).

\section{Surgical procedures}

The majority of patients ( $\mathrm{n}=151 ; 58 \%)$ underwent two-stage reconstruction using an expander followed by subsequent replacement by an implant. One-stage immediate breast reconstruction was less common ( $n=97 ; 38 \%$ ); one-stage reconstruction of the one side combined with two-stage reconstruction of the contralateral side was performed in 9 patients (4\%).

Ninety-seven women (37.74\%) had unilateral implant reconstruction; 7 of them had additional latissimus dorsi flap breast reconstruction with implant. Bilateral implant reconstruction was performed in 56 women (21.79\%), in 4 cases also with an additional latissimus dorsi flap.

Contralateral alignment of the breast - i.e., augmentation or reduction mammaplasty - was done in 102 patients (39.69\%). A titanized mesh was used with a dual-plane technique in 10

Table 2 Early complications (day 1-14).

\begin{tabular}{|c|c|c|c|}
\hline Complication & & $\mathbf{N}$ & $\%$ \\
\hline \multirow[t]{2}{*}{ Bleeding } & mild (no revision) & 5 & 1.95 \\
\hline & intense (revision) & 20 & 7.78 \\
\hline Fever/infection & & 16 & 6.23 \\
\hline Scar dehiscence & & 4 & 1.56 \\
\hline Impaired wound healing & & 13 & 5.06 \\
\hline
\end{tabular}

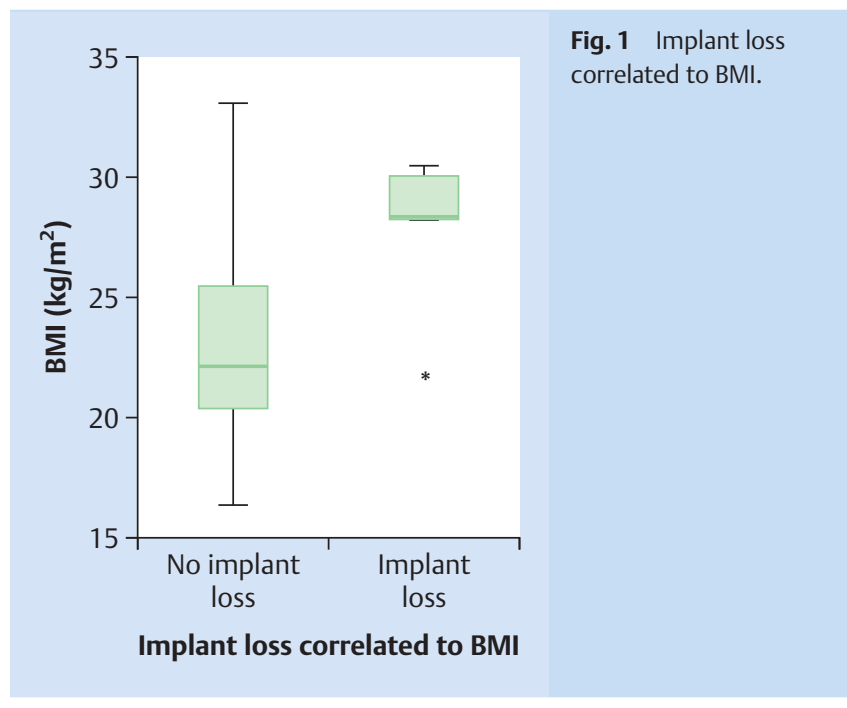

Table 3 Late complications (> 14 days post surgery) after implant reconstruction.

\begin{tabular}{|c|c|c|c|}
\hline Complication & & $\mathbf{n}$ & $\%$ \\
\hline \multirow[t]{3}{*}{ Keloid } & Total & 27 & 10.51 \\
\hline & marked & 15 & 5.48 \\
\hline & partially & 12 & 4.67 \\
\hline Scar dehiscence & & 9 & 3.5 \\
\hline \multirow{9}{*}{ Dysesthesia } & Total & 101 & 39.39 \\
\hline & - not defined further & 61 & 23.74 \\
\hline & - loss of sensation & 25 & 9.73 \\
\hline & - sensation of coldness & 7 & 2.7 \\
\hline & $\begin{array}{l}\text { coldness and loss } \\
\text { of sensation }\end{array}$ & 3 & 1.17 \\
\hline & > itching & 2 & 0.78 \\
\hline & $\begin{array}{l}\text { sensation of foreign } \\
\text { body }\end{array}$ & 1 & 0.39 \\
\hline & pressure & 1 & 0.39 \\
\hline & - hypersensitivity & 1 & 0.39 \\
\hline \multirow[t]{3}{*}{ Seroma } & Total & 20 & 7.78 \\
\hline & $>$ mild & 7 & 2.72 \\
\hline & - marked & 13 & 5.06 \\
\hline \multirow[t]{2}{*}{ Capsular fibrosis } & diagnosed by physician & 19 & 7.39 \\
\hline & according to patient & 5 & 1.95 \\
\hline \multirow[t]{4}{*}{ Implant removal } & Total & 5 & 1.95 \\
\hline & - due to infection & 2 & 0.78 \\
\hline & $\begin{array}{l}\text { due to recurrence/other } \\
\text { primary breast cancer }\end{array}$ & 2 & 0.78 \\
\hline & - due to capsular fibrosis & 1 & 0.39 \\
\hline Implant rotation & & 3 & 1.17 \\
\hline Implant displacement & & 16 & 6.23 \\
\hline Implant expulsion & & 2 & 0.78 \\
\hline \multirow[t]{3}{*}{ Rupture } & implant & 2 & 0.78 \\
\hline & expander & 1 & 0.39 \\
\hline & not stated & 1 & 0.39 \\
\hline $\begin{array}{l}\text { Restriction } \\
\text { of movement }\end{array}$ & & 49 & 19.07 \\
\hline $\begin{array}{l}\text { Implant removal } \\
\text { on demand }\end{array}$ & & 5 & 1.95 \\
\hline \multirow[t]{3}{*}{ Exchange of implant } & Total & 11 & 4.28 \\
\hline & once & 10 & 3.89 \\
\hline & twice & 1 & 0.39 \\
\hline
\end{tabular}




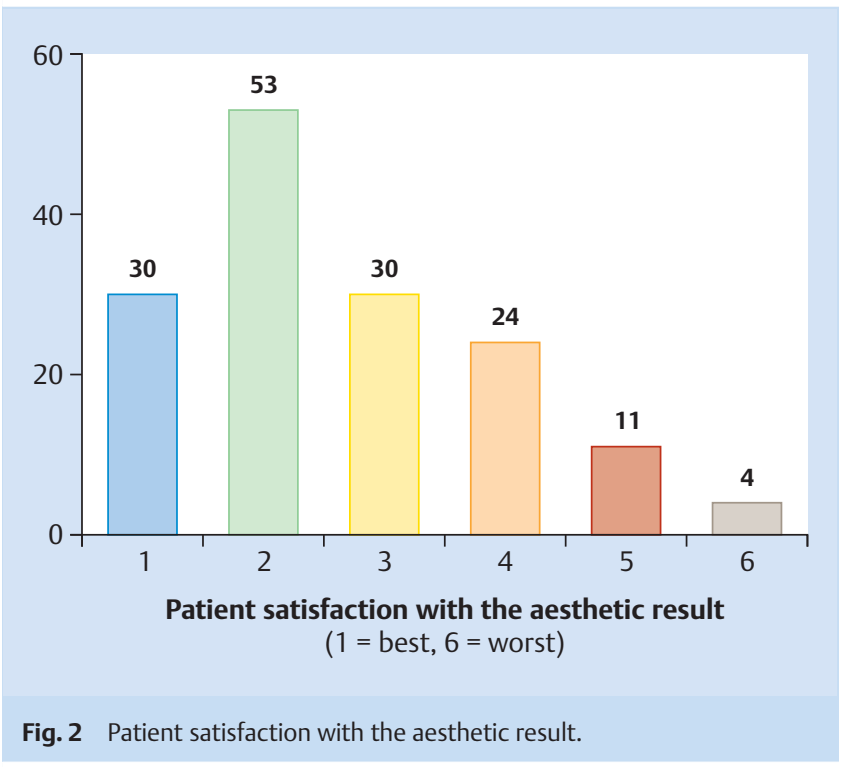

(3.89\%) of 257 patients; in 157 cases (61.09\%) corial flap was used for coverage of the lower breast pole. Seventy-one patients (27.63\%) with deferred breast reconstruction had secondary nipple-areola reconstruction.

\section{Complications}

Bleeding was reported as an early complication in 25 (9.73\%) of 257 women; 16 (6.23\%) had infection and fever, 13 (5.06\%) reported impaired wound healing, and $4(1.56 \%)$ had scar insufficiency (० Table 2).

The following late complications were recorded: dysesthesia in 101 cases (39.39\%); any type of restriction of arm movement in 49 patients (19.07\%); keloid scarring in 27 women (10.51\%); capsular fibrosis 24 cases (9.34\%); seroma in 20 cases (7.78\%); and scar insufficiency in 9 cases (3.5\%).

It was notable that impaired wound healing, scar insufficiency and dehiscence occurred more often in smokers. Of all the patients who were smokers -9 patients who smoked less than 5 cigarettes, 22 patients who smoked 5-10 cigarettes, and 17 patients who smoked more than 10 cigarettes per day - only the last group had an increased number of complications related to wound healing, with impaired wound healing found in 11.76\% and scar insufficiency in 5.88\%. Former smokers, even those who had only stopped smoking within the last 3 years, did not experience any increase in these complications.

Implant rotation occurred in 19 cases $(7.4 \%)$ and loss of implant in 4 cases $(1.56 \%)$. The implant had to be removed because of local recurrence in 2 cases $(0.78 \%$ ) and due to infection in another 2 cases $(0.78 \%)$. The infection rate in our cohort was comparatively low, with an incidence of $5.08 \%(n=3)$ in the group of patients where drainage remained in situ for $1-7$ days, $3.18 \%(n=3)$ in the group where drainage remained in place for 8-14 days, and $8.75 \%$ in the group where drainage remained for $15-21$ days, and $50 \%$ in the group were drainage remained in situ for more than 21 days $(\mathrm{n}=2)$. $\mathbf{O}$ Table 3 lists the late complications after implant reconstruction.

The factors influencing implantation rotation or loss were analyzed. Patients with higher BMI were more prone to implant rotation and implant loss, as shown in $\mathbf{O}$ Fig. 1. Meshes protected
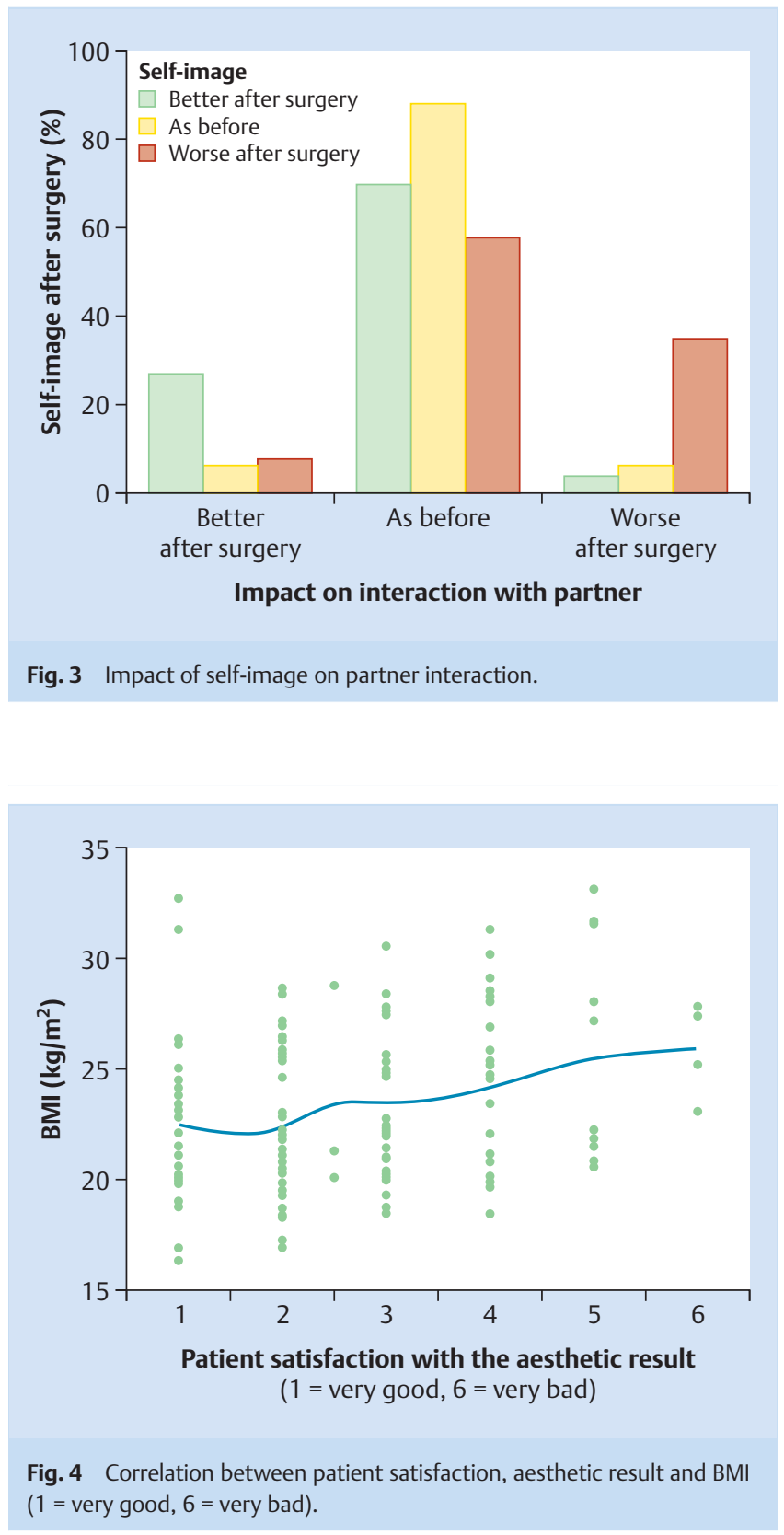

against implant rotation $(\mathrm{p}=0.034)$. Other examined factors did not influence implant rotation or loss.

\section{Patient-reported outcome (PRO)}

Questionnaires investigated mid- and long-term complications and patient satisfaction with the surgical outcome. A total of 185 out of 257 patients (71.98\%) responded to the questionnaires. Eighty-eight patients ( $47.57 \%$ ) reported a better body image after mastectomy and reconstruction; 35 (18.92\%) reported no change, and only 29 (15.68\%) reported a deterioration in body image. The patient's partner described the surgical outcome as improved in 26 cases (14.05\%), as no-change in 103 cases (55.7\%), and as deteriorated in 14 cases $(7.57 \%)$.

Around $73 \%$ of women (122/167) reported no pain or almost no pain (score 1-4) on a pain scale from 1 (excellent, no pain) to 10 (worst pain). 


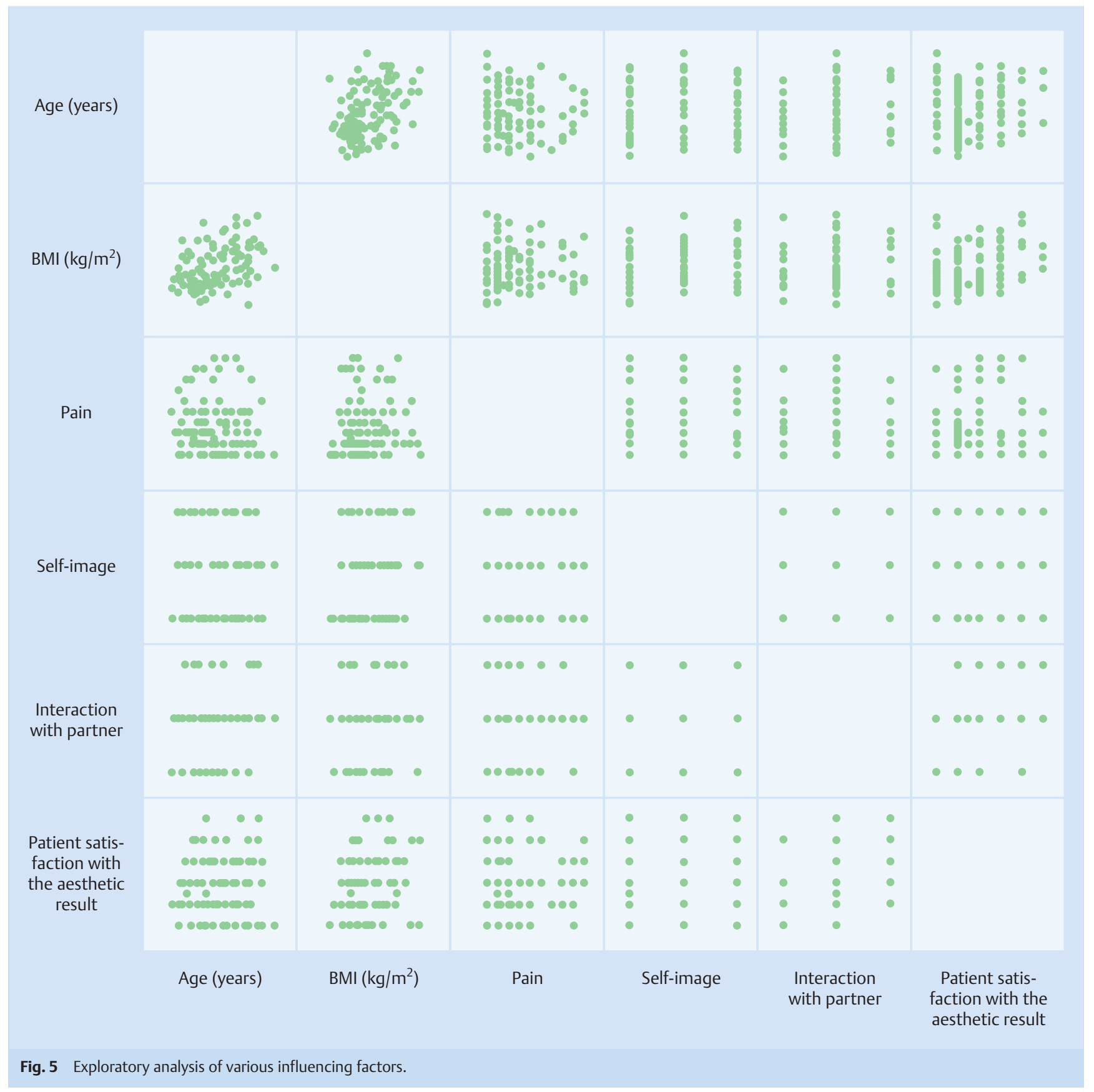

The aesthetic result after breast reconstruction was rated by the women using a scale from 1 (excellent) to 6 (failure). One hundred and three patients (74\%) expressed their satisfaction with the surgical result, giving it a rating of 1 (excellent), 2 (good), or 3 (satisfactory). 0 Fig. 2 shows the distribution of ratings.

\section{Analysis of patient-reported outcome}

A good aesthetic result was associated with a better self-image $(p=0.0001)$, and this also correlated with partner assessment $(p=0.0001)$ ( $\bullet$ Fig. 3). A good aesthetic result was also associated with less postoperative pain. Similarly, a positive self-image after reconstruction also correlated with a lower pain rating $(\mathrm{p}<0.001)$. Patients with a higher BMI reported a worse patientreported aesthetic outcome $(p=0.004)$, as shown in $\odot$ Fig. 4 . Ad- ditional correlations between age or BMI and PRO parameters are shown in Fig. 5. An overview of other correlations is shown in - Table 4.

\section{Adherence to decision}

Finally, patients were asked whether they considered reconstruction to have been the right choice and whether they would opt for the same surgery again. The majority of patients confirmed that reconstruction had been the right decision (145 patients [78.38\%] vs. 10 patients [5.41\%]). A total of 139 patients (75.14\%) would opt for the same type of surgery again vs. 15 patients $(8.11 \%)$ who would not.

Use of mesh protected against implant rotation. Self-image with mesh was better compared to corial flap. 
Table 4 Significant correlations between variables in implant-based breast reconstruction.

\begin{tabular}{|c|c|c|}
\hline Variable 1 & Variable 2 & p-value \\
\hline Mesh & Implant dislocation (lower) & 0.034 \\
\hline Corial flap & Self-image (better) & 0.002 \\
\hline Aesthetic result (worse) & BMI (higher) & 0.004 \\
\hline $\begin{array}{l}\text { Aesthetic result } \\
\text { (better/worse) }\end{array}$ & Age (higher) & 0.054 \\
\hline Self-image (better) & Interaction with partner (better) & 0.0001 \\
\hline Aesthetic result (better) & Pain (less) & 0.038 \\
\hline Aesthetic result (better) & Self-image (better) & 0.0001 \\
\hline $\begin{array}{l}\text { Interaction with partner } \\
\text { (better) }\end{array}$ & Aesthetic result (better) & 0.002 \\
\hline BMI & Implant loss (higher rate) & 0.005 \\
\hline $\mathrm{BMI}$ & Implant dislocation (higher rate) & 0.014 \\
\hline
\end{tabular}

\section{Discussion}

$\nabla$

We explored various patient and surgery-related characteristics influencing the surgical outcome after breast reconstruction with implant. Obesity and smoking > 10 cigarettes per day had a negative impact on implant reconstruction results. A higher BMI (>30) made patients more prone to implant loss and dislocation, and aesthetic results were rated as less favorable in obese patients. Autologous reconstruction may be an option offering a higher patient satisfaction for this group.

Age in itself did not seem to be a contraindication for implant breast reconstruction; it did not have a negative impact on aesthetic outcome or patient satisfaction. It should be noted that the oldest patients with breast reconstruction in our study were 79 years old and they were highly satisfied with the aesthetic result.

We also found evidence that a good aesthetic result is associated with less pain after surgery and that it also corresponded with a good partner interaction. The use of corial flap or titanized mesh had a positive impact on self-image, and titanized polypropylene meshes prevented implant loss.

Use of the minimal touch technique for implant insertion and antibiotic prophylaxis as long as drainage remains in place resulted in a low infection rate of $6 \%$ in our cohort as well as a low capsular contraction rate of $<10 \%$ and minimal implant loss of $<2 \%$ at 3.1 years' follow-up.

This study shows which patients have a higher risk of an unfavorable outcome after implant reconstruction and which surgical devices could reduce implant complications. Our findings could be used in pre-surgical counselling of patients desiring breast reconstruction after mastectomy.

Breast reconstruction with an expander and implant is currently being investigated in a number of studies, especially with regard to sequelae such as capsular fibrosis. In a review of 49 publications, each with a minimum follow-up time of one year, Kronowitz et al. [10], reported that capsular fibrosis occurs in more than $40 \%$ of patients. Whitfield et al. [11], Cowen et al. [12] and Piroth et al. [13] detected significant differences in the frequency of capsular fibrosis between patients with and those without radiotherapy. A review by Lam et al. [14] confirmed a higher implant failure rate in patients undergoing radiotherapy. In our study, the rate of capsular fibrosis was low, at $6.25 \%$ after a median follow-up of 3.1 years. This differs from the results reported in other studies. Late sequelae such as implant failure in patients with radiotherapy did not occur in our study. Baschnagel et al. [15], demonstrated that even with radiotherapy, implant-based breast reconstruction is feasible with a good cosmetic result and an acceptable rate of implant loss/failure (9.7\% after 1 year, $19.3 \%$ after 2 years and $25.5 \%$ after 3 years).

The correlation between infection and fever and the duration of antibiotic therapy was also analyzed. Infection occurred in 16 cases $(6.23 \%)$, a rate that is markedly lower than the rate reported by Washer et al. [16]. Patients who received antibiotic prophylaxis for more than two weeks did not suffer from any infection. This demonstrates the beneficial effect of antibiotic prophylaxis in implant reconstruction.

No significant differences in surgical outcome associated with the length of antibiotic prophylaxis were detected in the first two weeks after surgery. A retrospective study by Weichmann et al. [17] recommended the use of oral fluorquinolones as primary prophylaxis, based on their finding of an infection rate of $4.8 \%$ after implant reconstruction which necessitated removal of the implant.

The infection rate in our cohort was similarly low at $5.08 \%(n=3)$ in the group of patients with drainages remaining in place for 1-7 days, $3.18 \%(n=3)$ in patients where drainage remained in place for 8-14 days, $8.75 \%$ in patients where drainage remained for $15-$ 21 days, and $50 \%$ in patients where drainage remained in place for more than 21 days $(n=2)$.

Seroma occurred in 5.6\% (13) of patients in all three groups (1-7 days, 8-14 days, 15-21 days) without significant differences between groups. However, no seroma occurred in the group where drainage remained in place for $>21$ days. Spear et al. [18], explored the occurrence of late seroma ( 1 to 4.7 years) after augmentation and implant reconstruction in 25 patients with $28 \mathrm{op}-$ erations. They reported that seroma were idiopathic, without clear evidence of infection or malignancy in the majority of cases. Drainages had been placed before seroma occurrence in all cases. Complete capsulectomy was performed in $61 \%$ of cases, and implant removal or a combination of capsulectomy procedure and implant removal was done in $64 \%$ of cases. The median followup in our study was 41 months (3.4 years) after implant reconstruction - one year longer than in Spears' cohort. In our cohort, implant removal was only required in one woman with seroma (due to capsular fibrosis).

Patient satisfaction was an important issue in our analysis. Case cohort studies often compare heterogeneous groups with autologous or heterologous reconstruction. In the study by $\mathrm{Hu}$ et al. [19], patient satisfaction in the first 5 years after the procedure did not differ between TRAM flap and expander-implant reconstruction. However, as Bodin et al. [20] demonstrated, patient satisfaction subsequently decreases in later years in the group with heterologous reconstruction. In our study, patient satisfaction reached its maximum level in the first year after surgery (30.77\% rated their satisfaction with the outcome after surgery as "very good" and $23.08 \%$ as "good") and decreased in subsequent years. Yueh et al. [21] reported an overall satisfaction with expander-implant reconstruction of $56.5 \%$. If we group together the ratings "very good", "good" and "satisfactory" achieved in our cohort as overall satisfaction, then our results are even higher at $61.08 \%$. Koslow et al. [22] reported that contralateral prophylactic mastectomy combined with immediate reconstruction also had a positive impact on patient satisfaction.

Fischer et al. [23] examined risk factors and found them to be significantly associated with higher BMI $(p<0.0001)$, higher age ( $p<0.001)$, obesity $(p<0.001)$, smoking $(p<0.0001)$, and hyper- 
tension ( $\mathrm{p}<0.001)$. These findings were confirmed in multivariate regression analysis (age $>55$ years: $O R=2.0, p=0.004$; obesity $\left[\mathrm{BMI} \geq 30 \mathrm{~kg} / \mathrm{m}^{2}\right]$ : OR $1.7, \mathrm{p}=0.03 ;$ smoking: $\mathrm{OR}=4.0$; $\mathrm{p}<0.004)$. In our cohort, BMI was confirmed as an independent risk factor for implant loss (BMI $\left.>30 \mathrm{~kg} / \mathrm{m}^{2} ; \mathrm{p}=0.005\right)$. Impaired wound healing and scar insufficiency only occurred in the group of patients smoking > 10 cigarettes; however, this finding did not reach statistical significance $(\mathrm{p}=0.069)$.

Ho et al. [24] investigated the long-term outcomes for patients with expander-implant reconstruction and post-mastectomy radiotherapy. Between 1996 and 2006, 1639 patients underwent modified radical mastectomy, 751 of whom had immediate expander placement. A total of 151 of these patients received chemotherapy, with replacement of the expander by a permanent implant and radiotherapy. After a median follow-up of 86 months, 21 implants had been exchanged (17.1\%) and 17 implants had been removed (13.3\%). Reasons for implant removal were infection, implant failure (rupture, leak), patient request or multifactorial [24].

In our case cohort study, the rate of implant exchange was comparably low at $4.28 \%(n=11)$. Implant removal was performed in 10 patients (3.90\%). Reasons for implant removal included patient request in 5 cases, infection in 2 cases, in-breast recurrence or development of another primary breast cancer in another 2 cases and capsular fibrosis in one case. Implant rupture was recorded separately in our study and only occurred in two cases $(0.78 \%)$, which was lower compared to the rate in Ho's study. Our rate refers to the whole cohort whereas in Ho's study, it refers only to post-radiotherapy patients. None of the 35 patients with implant reconstruction and radiotherapy in our study experienced implant loss. A recent study by Jagsi et al. [25] on US trends in breast reconstruction for women undergoing mastectomy showed that autologous techniques are used more often in patients who have both reconstruction and radiotherapy (OR 1.8; $\mathrm{p}<0.001$ ). However, our data suggests that a combination of radiotherapy and implant reconstruction is feasible, provided that patients are aware of potential sequelae.

\section{Conclusion}

This case cohort study of patients with expander-implant reconstruction demonstrates the safety of heterologous reconstructions, with low rates of complications and high levels of patient satisfaction. The majority of patients expressed their satisfaction with the surgical result in study questionnaires and would opt for the same operation again, demonstrating a strong adherence to their decision.

Patient characteristics such as high BMI - but not smoking less than 10 cigarettes/day or higher age - had a negative impact on patients' self-image after implant reconstruction and led to higher rates of implant loss. Patients with a high consumption of cigarettes and/or obesity should be aware of the risk of an unfavorable aesthetic outcome after implant reconstruction.

The use of polypropylene mesh protected against implant displacement and the prophylactic use of antibiotics was confirmed as beneficial to avoid implant pouch infection. A good aesthetic result was found to be correlated with lower postoperative pain and a better self-image and body image. The aesthetic result did not vary with age. With a high degree of satisfaction reported across all age groups, elderly patients can also be encouraged to undergo implant reconstruction as a shorter and less time-consuming procedure.

\section{Acknowledgements}

\section{$\nabla$}

We would like to thank André Scherag, Professor of Clinical Epidemiology, University of Jena, and Hildegard Lax, Institute of Medical Informatics, Biometry and Epidemiology, University of Duisburg-Essen, for their contribution to the statistical analysis.

\section{Conflict of Interest \\ $\nabla$}

None.

\section{References}

1 Eisemann N, Waldmann A, Katalinic A. Epidemiology of breast cancercurrent figures and trends. Geburtsh Frauenheilk 2013; 73: 130-135

2 Fasching PA, Ekici AB, Wachter DL et al. Breast cancer risk - from genetics to molecular understanding of pathogenesis. Geburtsh Frauenheilk 2013; 73: 1228-1235

3 Maass N, Schutz F, Fasching PA et al. Breast cancer update 2014 - focus on the patient and the tumour. Geburtsh Frauenheilk 2015; 75: 170182

4 Veronesi U, Cascinelli N, Mariani L et al. Twenty-year follow-up of a randomized study comparing breast-conserving surgery with radical mastectomy for early breast cancer. N Engl J Med 2002; 347: 12271232

5 Fisher B, Anderson S, Bryant J et al. Twenty-year follow-up of a randomized trial comparing total mastectomy, lumpectomy, and lumpectomy plus irradiation for the treatment of invasive breast cancer. $\mathrm{N}$ Engl J Med 2002; 347: 1233-1241

6 Jud SM, Fasching PA, Maihofner C et al. Pain perception and detailed visual pain mapping in breast cancer survivors. Breast Cancer Res Treat 2010; 119: 105-110

7 Bani MR, Beckmann K, Engel J et al. Correlates of the desire for improved cosmetic results after breast-conserving therapy and mastectomy in breast cancer patients. Breast 2008; 17: 640-645

8 Bani MR, Lux MP, Heusinger K et al. Factors correlating with reexcision after breast-conserving therapy. Eur J Surg Oncol 2009; 35: 32-37

9 Fernandez-Delgado J, Lopez-Pedraza MJ, Blasco JA et al. Satisfaction with and psychological impact of immediate and deferred breast reconstruction. Ann Oncol 2008; 19: 1430-1434

10 Kronowitz SJ, Robb GL. Radiation therapy and breast reconstruction: a critical review of the literature. Plast Reconstr Surg 2009; 124: 395408

11 Whitfield GA, Horan G, Irwin MS et al. Incidence of severe capsular contracture following implant-based immediate breast reconstruction with or without postoperative chest wall radiotherapy using 40 Gray in 15 fractions. Radiother Oncol 2009; 90: 141-147

12 Cowen D, Gross E, Rouannet P et al. Immediate post-mastectomy breast reconstruction followed by radiotherapy: risk factors for complications. Breast Cancer Res Treat 2010; 121: 627-634

13 Piroth MD, Piroth DM, Pinkawa M et al. Immediate reconstruction with an expander/implant following ablatio mammae because of breast cancer: side effects and cosmetic results after adjuvant chest wall radiotherapy. Strahlenther Onkol 2009; 185: 669-674

14 Lam TC, Hsieh F, Boyages J. The effects of postmastectomy adjuvant radiotherapy on immediate two-stage prosthetic breast reconstruction: a systematic review. Plast Reconstr Surg 2013; 132: 511-518

15 Baschnagel AM, Shah C, Wilkinson JB et al. Failure rate and cosmesis of immediate tissue expander/implant breast reconstruction after postmastectomy irradiation. Clin Breast Cancer 2012; 12: 428-432

16 Washer LL, Gutowski K. Breast implant infections. Infect Dis Clin North Am 2012; 26: 111-125

17 Weichman KE, Levine SM, Wilson SC et al. Antibiotic selection for the treatment of infectious complications of implant-based breast reconstruction. Ann Plast Surg 2013; 71: 140-143

18 Spear SL, Rottman SJ, Glicksman C et al. Late seromas after breast implants: theory and practice. Plast Reconstr Surg 2012; 130: 423-435

$19 \mathrm{Hu}$ ES, Pusic AL, Waljee JF et al. Patient-reported aesthetic satisfaction with breast reconstruction during the long-term survivorship Period. Plast Reconstr Surg 2009; 124: 1-8 
20 Bodin F, Zink S, Lutz JC et al. [Which breast reconstruction procedure provides the best long-term satisfaction?]. Ann Chir Plast Esthet 2010; 55: 547-552

21 Yueh JH, Slavin SA, Adesiyun T et al. Patient satisfaction in postmastectomy breast reconstruction: a comparative evaluation of DIEP, TRAM, latissimus flap, and implant techniques. Plast Reconstr Surg 2010; 125: 1585-1595

22 Koslow S, Pharmer LA, Scott AM et al. Long-term patient-reported satisfaction after contralateral prophylactic mastectomy and implant reconstruction. Ann Surg Oncol 2013; 20: 3422-3429
23 Fischer JP, Nelson JA, Serletti JM et al. Peri-operative risk factors associated with early tissue expander (TE) loss following immediate breast reconstruction (IBR): a review of 9305 patients from the 2005-2010 ACS-NSQIP datasets. J Plast Reconstr Aesthet Surg 2013; 66: 15041512

24 Ho A, Cordeiro P, Disa J et al. Long-term outcomes in breast cancer patients undergoing immediate 2-stage expander/implant reconstruction and postmastectomy radiation. Cancer 2012; 118: 2552-2559

25 Jagsi R, Jiang J, Momoh AO et al. Trends and variation in use of breast reconstruction in patients with breast cancer undergoing mastectomy in the United States. J Clin Oncol 2014; 32: 919-926 